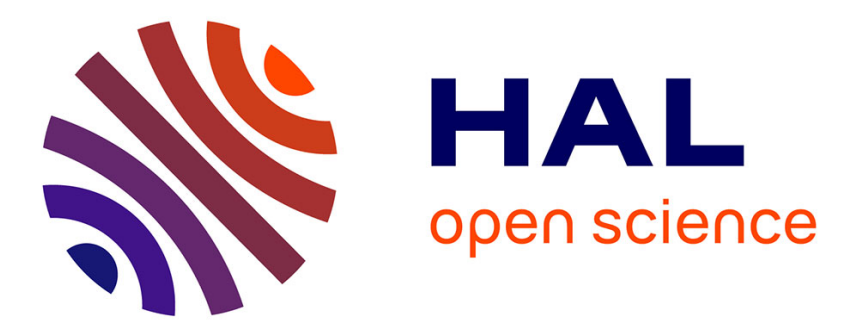

\title{
Non-heme iron hydroperoxo species in superoxide reductase as a catalyst for oxidation reactions
}

\author{
S. Rat, S. Ménage, F. Thomas, V. Nivière
}

\section{To cite this version:}

S. Rat, S. Ménage, F. Thomas, V. Nivière. Non-heme iron hydroperoxo species in superoxide reductase as a catalyst for oxidation reactions. Chemical Communications, 2014, 50, pp.14213-6. $10.1039 / \mathrm{c} 4 \mathrm{cc} 06114 \mathrm{~d}$. hal-01076174

HAL Id: hal-01076174

https://hal.univ-grenoble-alpes.fr/hal-01076174

Submitted on 21 Oct 2014

HAL is a multi-disciplinary open access archive for the deposit and dissemination of scientific research documents, whether they are published or not. The documents may come from teaching and research institutions in France or abroad, or from public or private research centers.
L'archive ouverte pluridisciplinaire HAL, est destinée au dépôt et à la diffusion de documents scientifiques de niveau recherche, publiés ou non, émanant des établissements d'enseignement et de recherche français ou étrangers, des laboratoires publics ou privés. 


\section{Non-heme iron hydroperoxo species in superoxide reductase as a catalyst for oxidation reactions ${ }^{+}$}

Cite this: DOI:

Received,

Accepted

DOI:
S. Rat, ${ }^{a, b, c}$ S. Ménage ${ }^{a, b, c}$, F. Thomas ${ }^{d}$ and V. Nivière ${ }^{a, b, c^{*}}$

\begin{abstract}
The non-hemehigh-spin ferric iron hydroperoxo species formed in superoxide reductase catalyzesoxidative aldehyde deformylation through its nucleophile character.This species also acts as an electrophile to catalyze oxygen atom transfer in sulfoxidation reactions, highlighting the oxidation potential of non-heme iron hydroperoxo species.
\end{abstract}

The mechanisms of oxygen activation and oxidation reactions catalyzed by metalloenzymes have been thoroughly investigated during the last past decades. ${ }^{1-5}$ For cytochrome $\mathrm{P} 450{ }^{5,6}$ and several non-heme iron monooxygenases, $4,7,8_{\text {it }}$ is now well admitted that high-valent iron-oxo species formed at their active site is the effective oxidant for organic substrate oxidation and oxygen transfer. Nevertheless, the fact that alternative species, e.g. ferric iron (hydro)peroxide intermediate, ${ }^{1}$ or other metal-oxidant adducts, ${ }^{9}$, ${ }^{10}$ may be also directly involved in oxidation catalysis are currently the focus of a great interest. However, although the reactivity of ferric iron hydroperoxide species has been studied on synthetic hemes $^{11}$ and non-hemeiron complexes, ${ }^{1}$ 12-17 data on biological systems remain dramatically scarce, if not available. In cytochrome $\mathrm{P} 450$, which is one of the most studiedoxygenases, a ferric iron hydroperoxide species (compound 0 ) has been postulated to be the precursor of the high-valent iron species radical porphyrin (compound I). ${ }^{5}$ In spite of many efforts, compound 0 has never been directly observed experimentally, being essentially described by computational methods, ${ }^{18}$ or indirectly predicted from the analysis of reaction products. ${ }^{5}{ }^{19}$ Consequently, the reactivity of compound 0 towards substrates cannot be directly investigatedin cytochrome P450. Superoxide reductase (SOR), a small non-heme mononuclear iron protein, involved in superoxide radical detoxification in some microorganisms, ${ }^{20-22}$ presents some interesting similarities with the cytochrome $\mathrm{P} 450$ oxygenase. ${ }^{23}$ First, both enzymes have a mononuclear iron site with a same $\left[\mathrm{N}_{4} \mathrm{~S}_{1}\right]$ coordinationgeometry, the sulfur axial ligand being provided by a cysteine residuein the two systems. ${ }^{5,22,}{ }^{24}$ The four nitrogen ligands come froma porphyrin ring in $\mathrm{P} 450,{ }^{5}$ whereas they are provided by four histidine residues in
SOR. ${ }^{22,}{ }^{24}$ Second, SOR, as $\mathrm{P} 450,{ }^{18}$ also involves an iron ferric hydroperoxideas a key intermediate in its catalytic mechanism. In SOR, this species has been trapped and thoroughly characterized. High resolution RX structures, ${ }^{24}$ resonance Raman $(\mathrm{RR})^{25-27}$ and Mössbauer spectroscopies ${ }^{28}$ revealed that the hydroperoxideformed in SOR coordinates in aend-on fashion a high spin $(S=5 / 2)$ iron center. Such investigations were possible because two mutations on well conserved second coordination sphere residues of the SOR from Desulfoarculusbaarsii, $\mathrm{E}_{47 \mathrm{~A}^{25}}$ and $\mathrm{E} 114 \mathrm{~A}^{24,}{ }^{27}$, allow for an accumulation of the iron ferric hydroperoxide intermediate when the enzyme was rapidly reacted with a slight excess of $\mathrm{H}_{2} \mathrm{O}_{2}$. For the E47A mutant, Mössbauer studies demonstrated that in these conditions, the SOR active site was at $95 \%$ in the iron ferric hydroperoxide form. ${ }^{28}$ The E114A mutantexhibitsRR bands associated to the iron ferric hydroperoxide with a same intensity than those characterized for theE47A mutant. ${ }^{27}$ This suggests that in the E114A mutant, the active site is also fully underan iron ferric hydroperoxide form. Interestingly, a third SOR mutant, wherein another second coordination sphere residue, I118, wasmutated into serine, ${ }^{29}$ exhibits a different reactivity. When it is incubated with $\mathrm{H}_{2} \mathrm{O}_{2}$, a high-valent iron-oxo species is quickly formed. ${ }^{30}$ This species presumably results from the cleavage of the $\mathrm{O}-\mathrm{O}$ bond of the iron ferric hydroperoxide intermediate, which was favored in this mutant. Thus, thecontrol on the nature of the oxygen adducts (iron ferric hydroperoxide or iron-oxo species)in theSOR mutants opens the door for comparative reactivitystudiesin oxidation reactions.

In order to investigate the reactivity of the SOR ferric hydroperoxide intermediate, we tested the ability of the $D$. baarsiiSOR wild-type, E47A, E114A and I118S mutant forms to perform oxidative aldehyde deformylationin the presence of $\mathrm{H}_{2} \mathrm{O}_{2}$ (ESI). This reaction that requires a nucleophilic attack on the aldehyde was reported to be carried out by ferric iron (hydro)peroxo species, ${ }^{12},{ }^{13},{ }^{31}$ whereas the electrophilic iron-oxo species wouldoxidize aldehydes into their corresponding acid. ${ }^{13}$ The reaction wasconducted under anaerobic conditions, in the presence of $\mathrm{CH}_{3} \mathrm{CN}$ (4 M)in order to ensure a sufficient solubility of the organic substrates(Fig. 1). We observed that $\mathrm{CH}_{3} \mathrm{CN}$ at the concentration of 
$4 \mathrm{M}$ did not affect the stability of SOR,at least during $30 \mathrm{~min}$ at room temperature(data not shown). In the absence of SOR, no oxidation products were detected by GC. In the presence of SOR, phenylacetaldehyde was oxidized into benzaldehyde as a majority, without formation of phenylacetic acid (Fig. 1). The yield of benzaldehyde was about $20-37 \%$ with respect to the SOR forms, in the presence of 1 molar equivalent of $\mathrm{H}_{2} \mathrm{O}_{2}$ (Fig. 1).

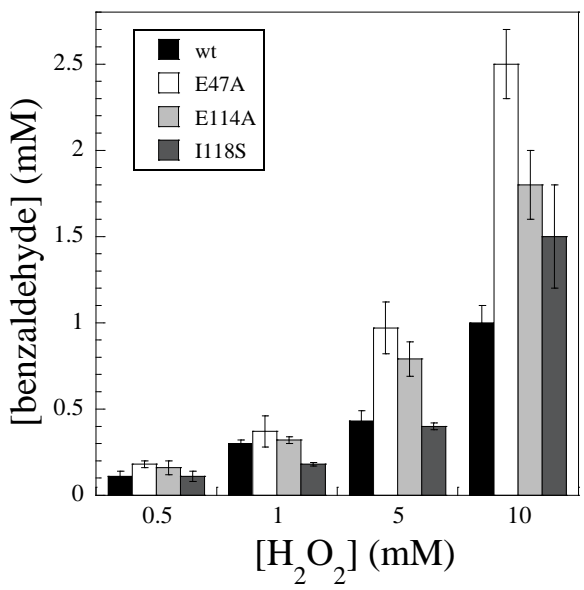

Fig. 1.Oxidative decarboxylation of phenylacetaldehyde into benzaldehyde catalyzed by the D. baarsiiSOR wild-type, E47A, E114A or I118S, mutant forms $(1 \mathrm{mM}$ of SOR, $15 \mathrm{mM}$ of phenylacetaldehyde, $10 \mathrm{mMTris} / \mathrm{HCl} \mathrm{pH}$ $8.5,4 \mathrm{M} \mathrm{CH}_{3} \mathrm{CN}$ ) in the presence of $0.5-10$ equiv $\mathrm{H}_{2} \mathrm{O}_{2}$, under $\mathrm{N}_{2}$ atmosphere at $20{ }^{\circ} \mathrm{C}$.The iron active site of SORs was in a ferrous state when added to the reaction mixture. After 2 min reaction time, benzaldehyde formation was analyzed by GC.

With 10 equiv. of $\mathrm{H}_{2} \mathrm{O}_{2}$, up to 2.5 turn-overs were observed in the case of the E47A SOR mutant (Fig. 1). Increasing the reaction time to $10 \mathrm{~min}$ did not affect the yield in benzaldehyde, showing that the reaction was completed within $2 \mathrm{~min}$. In the presence of 10 equiv. of $\mathrm{H}_{2} \mathrm{O}_{2}$ (Table 1),i.e. the conditions that yieldedthe largest amount of benzaldehyde, formateproduction was observed. The relative formate amounts were 30, 26, 52 and $64 \%$ of that of benzaldehyde, for the wild-type, I118S, E114A and E47A SOR forms, respectively (Table 1). GC analysis also evidenced formation of benzyl formate with all the SOR forms, in an amount of about 10$20 \%$ of that of benzaldehyde (Table 1) $\$$. When the reaction was carried out with 10 equiv. of $\mathrm{H}_{2}{ }^{18} \mathrm{O}_{2}$, analysis of the products by mass spectrometry showed that $87 \pm 8 \%$ of theoxygen incorporated intothe benzaldehydeproduct was originated from the ${ }^{18} \mathrm{O}$-labeled peroxide. The small amount of ${ }^{16} \mathrm{O}$ labeled form might originate from oxygen exchange of the transient $\mathrm{Fe}^{3+}-\mathrm{O}^{\bullet}$ species (see below) with the solvent.

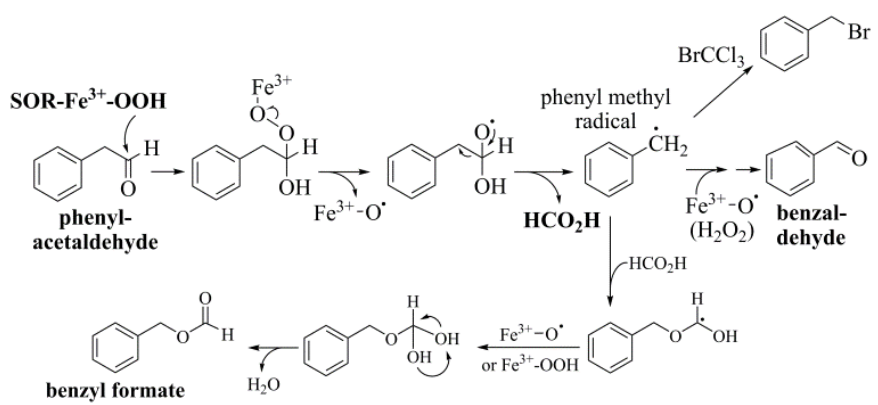

Scheme 1. Proposed mechanism for the deformylation reaction catalyzed by the ferric iron hydroperoxide species formed in SOR, as described in reference ${ }^{19}$.
The fact that benzaldehyde, formate and benzyl formate(Table 1) could be detected as products suggests that the reaction mechanism is similar to that proposed for the deformylation reaction catalyzed by the ferric (hydro)peroxo intermediate in cytochrome P450 (Scheme 1). ${ }^{19}$ In thismechanism, anucleophilic addition of the ferric (hydro)peroxo species on the aldehyde affords a peroxyhemiacetaladduct, which then undergoes a radical fragmentation to generate formate. The transient $\mathrm{Fe}^{3+}-\mathrm{O}^{\bullet}$ species, and also possibly $\mathrm{H}_{2} \mathrm{O}_{2}$ still present in the solution, could further oxidize the phenyl methyl radicalintermediateinto benzaldehyde, without accumulation of benzyl alcohol. That such a phenyl methyl radical species was transiently generated during the reaction of SOR with phenyl-acetaldehyde was confirmed by performing the reaction in the presence of an excess of $\mathrm{BrCCl}_{3}$. In these condition $\mathrm{PhCH}_{2} \mathrm{Br}$, which results from the quenching of the phenyl methyl radical species by $\mathrm{BrCCl}_{3}$, was detected by $\mathrm{GC}$ analysis, whereas production of benzaldehyde was significantly decreased (Table 1, Scheme 1). Finally,the formation of a small amount ofbenzyl formatemightbe explained as follow:the phenyl methyl radical could attack the carbonyl oxygen of the formic acid to give a carbon-centered radical that could be further hydroxylated by the $\mathrm{Fe}^{3+}-\mathrm{O}^{\bullet}$ or $\mathrm{Fe}-\mathrm{OOH}$ species. It would follow a rearrangement and an elimination of a water molecule (Scheme 1).Alternatively, as proposed in reference ${ }^{19}$, benzyl formate might result from an oxidation of the phenyl methyl radical into a carbocation species and a further reaction with formate.Note that as shown in Table 1, the mass balance is not equilibrated. Since a radical chemistry is involved, it is suspected that part of the radical intermediate reacted with the buffer and/or with the polypeptide chain.

Table 1.Reaction products for the deformylation of phenylacetaldehydein the presence of 10 equiv of $\mathrm{H}_{2} \mathrm{O}_{2}$. The experimental conditions are the same than in Fig.1. Benzaldehyde, benzyl formate and $\mathrm{PhCH}_{2} \mathrm{Br}$ were quantified by GC. Formate was quantifiedwitha formate dehydrogenase assay (ESI).

\begin{tabular}{|c|c|c|c|c|c|}
\hline \multirow[b]{2}{*}{$\begin{array}{l}\text { SOR } \\
\text { forms }\end{array}$} & \multicolumn{3}{|c|}{${\mathrm{No} \mathrm{BrCCl}_{3}}_{2}$} & \multicolumn{2}{|c|}{$500 \mathrm{mM} \mathrm{BrCCl}_{3}$} \\
\hline & $\begin{array}{l}\text { benzal- } \\
\text { dehyde } \\
(\mathrm{mM})\end{array}$ & $\begin{array}{l}\text { formate } \\
(\mathrm{mM})\end{array}$ & $\begin{array}{l}\text { benzyl } \\
\text { formate } \\
(\mathrm{mM})\end{array}$ & $\begin{array}{l}\text { benzal- } \\
\text { dehyde } \\
(\mathrm{mM})\end{array}$ & $\begin{array}{l}\mathrm{PhCH}_{2} \mathrm{Br} \\
\quad(\mathrm{mM})\end{array}$ \\
\hline wt & $1.0 \pm 0.1$ & $0.30 \pm 0.03$ & $0.10 \pm 0.01$ & $0.51 \pm 0.02$ & $0.03 \pm 0.01$ \\
\hline E47A & $2.5 \pm 0.2$ & $1.60 \pm 0.20$ & $0.20 \pm 0.02$ & $0.57 \pm 0.03$ & $0.20 \pm 0.02$ \\
\hline E114A & $2.1 \pm 0.2$ & $1.10 \pm 0.10$ & $0.20 \pm 0.02$ & $0.44 \pm 0.04$ & $0.19 \pm 0.02$ \\
\hline I118S & $1.5 \pm 0.3$ & $0.40 \pm 0.04$ & $0.10 \pm 0.01$ & $0.40 \pm 0.02$ & $0.04 \pm 0.01$ \\
\hline
\end{tabular}

2-phenylpropionaldehyde, a more stericallyhindered substrate, was also deformylated into acetophenoneby SOR (ESI). The yield was nevertheless much lower than that determined for phenylacetaldehyde (ESI).

Altogether, these data showed that the SOR from $D$. baarsiicarries out oxidative decarboxylation of aldehydesin the presence of $\mathrm{H}_{2} \mathrm{O}_{2}$ (Scheme 1). Theresults demonstrate that the ferric iron hydroperoxide species, which is formed in high yield in the $\mathrm{E} 47 \mathrm{~A}^{25,28}$ and $\mathrm{E} 114 \mathrm{~A}^{24,27}$ SOR mutants, acts as a catalytically competent nucleophile. Furthermore, $\mathrm{HO}^{\bullet}$ radical could not be involved in this process, since no formation of $\mathrm{HO}^{\bullet}$ was observed by spin trapping during the reaction of SOR with $\mathrm{H}_{2} \mathrm{O}_{2}$ (ESI).

Interestingly, the ferric iron hydroperoxide species was formed in a lower yield with the wild-type protein, ${ }^{26}$ which is in line with itslowerability to oxidize aldehyde (Fig. 1).The I118S SOR mutant, whichwas recently shown to form an iron-oxo species in the presence of $\mathrm{H}_{2} \mathrm{O}_{2},{ }^{30}$ was also able to carry out oxidative decarboxylation of aldehydes, albeit in a lower yield compared to the E47A and E114A SOR mutants (Fig. 1). Based on RR studies, it was proposed that the iron-oxo species formed in the I118S SOR mutant results from a rapid $\mathrm{O}-\mathrm{O}$ bond cleavage of a transiently formed iron 
hydroperoxide. ${ }^{30}$ This suggeststhe existence of two competitive pathways that consume the iron hydroperoxide species in this SOR mutant: conversion into the iron-oxo species or nucleophilic oxidation of aldehyde.

Oxidation of thioanisolewas investigated in similar conditions than those used for deformylation(Fig.2). No oxidation products of thioanisolecould be detected by GC in the absence of SOR.In the presence of SOR and 1molar equiv. of $\mathrm{H}_{2} \mathrm{O}_{2}$, thioanisole was oxidized into sulfoxide, in yields of 60 and $72 \%$ with respect to SOR for the wild-type and I118S proteins, respectively. The yield was slightly lower for the E47A and E114A mutants, 42 and $36 \%$, respectively (Fig. 2). In the presence of 10 equiv. of $\mathrm{H}_{2} \mathrm{O}_{2}$, the number ofturn-overs reached 2 with the wild-type andE47A SOR forms (Fig. 2). In all the cases, the reaction was completed within 2 $\min \S$ and no other oxidation products, e.g. sulfone, were detected by GC.

2-bromothioanisole and 2-methylthionaphthalene were also oxidized into sulfoxide by the four different SOR forms (ESI), albeit with a muchlower yield than thioanisole. For 2-bromothioanisole, this could reflect an electronic deactivation of the sulfide by the bromine, whereas for2-methylthionaphthalene, this could be due to its larger steric hindrance compared to thioanisole.

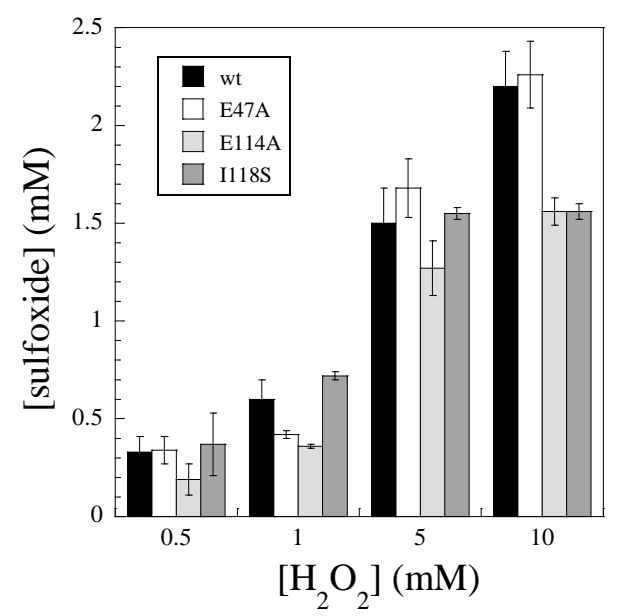

Fig. 2. Oxidation of thioanisole by the $D$. baarsiiSOR wild-type or E47A, E114A, I118S, mutant forms (1 mM of SOR, $15 \mathrm{mM}$ of thioanisole, 10

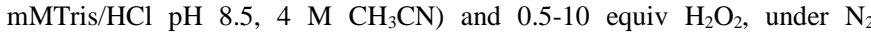
atmosphere at $20{ }^{\circ} \mathrm{C}$. The iron active site of SORswas in a ferrous state when added to the reaction mixture.After 2 min reaction time, sulfoxide formation was analyzed by GC.

These data show that the wild-type, E47A, E114A and I118S SORs catalysesulfoxidation of thioanisole in a comparable extent. No evidence supporting the formation of iron-oxo species in the presence of $\mathrm{H}_{2} \mathrm{O}_{2}$ were reportedfor the wild-type, E47A and E114A SORs. Thus,these resultsstrongly suggest that the ferric iron hydroperoxide speciesis the active species forsulfoxidation of thioanisole. For the I118S SOR mutant, the ferric iron hydroperoxide species, which wasrapidly formed in the presence of $\mathrm{H}_{2} \mathrm{O}_{2}$, might also be involved in the oxidation of thioanisole into sulfoxide. Nevertheless, we cannot exclude that theiron-oxospecies formed in this mutant ${ }^{20}$ was also involved in the sulfoxidation reaction.

Altogether, these data demonstrate that the ferric iron hydroperoxide species formed in the SOR active site can both act as a nucleophilefor oxidative decarboxylation of aldehyde, and as an electrophile to catalyze sulfoxidation of sulfides.

Finally, the electrophilic character of the ferric iron hydroperoxide and iron-oxo species formed in SOR mutants was also investigated in theepoxidationof styrene, cyclohex-2-en-1-ol, cyclooctene, and for the oxidation of weak $\mathrm{C}-\mathrm{H}$ bonds, with xanthene, 9,10-dihydro-anthracene, fluorene, cyclohexa-1,4-diene and ethylbenzene. In the presence from 0.5 to 10 equiv. of $\mathrm{H}_{2} \mathrm{O}_{2}$, we were unable to detect any oxidation product byGC with the four SOR forms (data not shown). Note thatthesecyclicsubstrates were tested at a concentration of $15 \mathrm{mM}$.Attempts to increase their concentrations beyond $15 \mathrm{mMin}$ the reaction mixtureinitiate precipitation, while acetonitrile concentration higher than 4 Mled to SOR instability.

It was rather unexpected that the iron-oxo species formed in the I118S SOR mutant was not potent for oxidation of any of the tested substrates. This result could be interpreted by steric hindrancesin the SOR iron site,impairinga proper positioning of the substrates to react with the oxidant.Further support for this hypothesis was provided by a study of the quenching of the SOR tryptophan fluorescence in the presence of the different substrates. The SOR from $D$. baarsiiindeed contains atryptophan residuelocated at about $8 \AA$ of the iron site,${ }^{24}$ which could be used as a probe to monitor interactions of putative substrate with the active site. In the presence of increasing concentration of phenylacetaldehyde and 2-bromothioanisole (thioanisoleis fluorescentand was not tested), the fluorescence of SOR was quenched in a saturable manner (ESI). These data are consistent with a specific binding of these two substrates (which were oxidized by SOR, see above) to the active site. The calculated $K_{\mathrm{d}}$ values areabout $1 \mathrm{mM}$ for phenylacetaldehyde and $3 \mathrm{mM}$ for 2-bromothianisole (ESI). A dramatically different behaviour was observed in the case of cyclohex-2-en-1-ol or cyclohexa-1,4-diene, which were not oxidized by SOR(ESI). Upon addition of increasing amounts of these substrates, the fluorescence increased linearly, without evidence for saturation. This change of fluorescence likely reflects a modification of the polarity of the solvent due to the addition of organicmoleculesrather than a specific interaction of these molecules with SOR. These data suggest that the alkylaromatic compounds cannot interactwith the polaractive site of SOR. ${ }^{24}$ Regarding thearomaticphenylacetaldehyde and thioanisole, which are oxidized by SOR,the aldehyde or sulfide groups would reachmore easily the active site, allowing reaction with the oxidant species. These data illustrate the major impact of the substrates binding site on the enzyme reactivity.

\section{Conclusion}

In summary, we report for the first time the reactivity of a nonhememononuclear high-spin ferric iron hydroperoxo species in a $\left[\mathrm{S}_{1} \mathrm{~N}_{4}\right]$ coordination set. ${ }^{24-28}$ This coordination set provided by SOR is reminiscent of that of cytochrome $\mathrm{P} 450$. However, the four equatorial ligands are histidine donors in SOR instead of pyrroles from theporphyrincofactor in P450 and the electric configuration of the iron center ishigh-spin in the iron hydroperoxo species of SOR instead of low-spin in $\mathrm{P} 450 .{ }^{18} \mathrm{We}$ showed that the high-spin iron hydroperoxo species formed in SOR catalysesdeformylation of aldehydes, demonstrating its ability to carry out oxidation through its nucleophilic character. In addition, it can act as an electrophilic species to catalyze oxygen atom transfer insulfoxidation reactions.Attempt to study its reactivity towards $\mathrm{C}-\mathrm{H}$ bond oxidation werenot yetpossible, most-likely due to the polar environment of the SOR iron site,whichprevents interactions with the alkylaromaticsubstratestested here.

The dual character of the SOR dioxygenadduct confirms the existence of the $\mathrm{Fe}^{3+}-\mathrm{OOH}$ reaction type.

Recently, a high-spin non-heme mononuclear iron hydroperoxo complex bearing a tetradentate $\mathrm{N}_{4}$ ligand was shown to carry out nucleophilic deformylation and electrophilic oxidations. ${ }^{12-15}$ Our present studies extent the reactivity of the iron hydroperoxo species 
to a $\left[\mathrm{N}_{4} \mathrm{~S}_{1}\right]$ coordination sphere in a non-heme protein environment and provide new evidence for the important role thatsuch a species could play in biocatalysis, especiallyinoxidation reactions.

The authors are grateful to the French National Agency for Research (ANR) «Programme Labex» (ARCANE project $n^{\circ} \mathrm{ANR}$ 11-LABX-003) for funding.

\section{Notes and references}

${ }^{a}$ Univ. Grenoble Alpes, iRTSV-LCBM, F-38000 Grenoble, France.

${ }^{b}$ CNRS, IRTSV-LCBM, F-38000 Grenoble, France.

${ }^{c}$ CEA, iRTSV-LCBM, F-38000 Grenoble, France.

${ }^{d}$ Département de Chimie Moléculaire - Chimie Inorganique Redox Biomimétique (CIRE) - UMR CNRS 5250, Univ. Grenoble Alpes, BP 53, 38041 Grenoble cedex 9, France.

E-mail: vniviere@cea.fr, Tel: 33438789109

$\dagger$ Electronic Supplementary Information (ESI) available: [Materials and experimental procedures; 2-phenylpropionaldehyde deformylation; Spin trapping experiments;Fluorimetric titrations of SORs with various substrates]. See DOI: 10.1039/c000000x/

$\$$ It was not possible to determine the redox state of the SOR iron active site at the end of the reactions, due to a partial alteration ofthe SOR iron sites during the course of the reactions.

$\S$ Because of a rather fast reaction time, detailed kinetics studies of sulfoxide formation by GC were hardly possible. In addition, phenyl methyl sulfide oxidation could not be followed by UV spectroscopy (maximum absorption at $250 \mathrm{~nm}$ ), sinceUV absorptioncontributions of the SOR protein also varied during the reaction.

M. Costas, M. P. Mehn, M. P. Jensen and L. Que, Jr., Chemical reviews, 2004, 104, 939

S. P. de Visser, J.-U. Rohde, Y.-M. Lee, J. Cho and W. Nam, Coordination Chemistry Reviews, 2013, 257, 381

A. R. McDonald and L Que Jr, Coordination Chemistry Reviews, 2013, 257, 414 Accounts of chemical research, 2007, 40,484 I. G. Denisov, T. M. Makris, S. G. Sligar and I. Schlichting, Chemical reviews, 2005, 105, 2253

J. Rittle and M. T. Green, Science, 2010, 330, 933

7 M. L. Matthews, C. M. Krest, E. W. Barr, F. H. Vaillancourt, C. T. Walsh, M. T. Green, C. Krebs and J. M. Bollinger, Biochemistry, 2009, 48, 4331

A. J. Panay, M. Lee, C. Krebs, J. M. Bollinger and P. F. Fitzpatrick, Biochemistry, 2011, 50, 1928

9 Z. Cong, S. Yanagisawa, T. Kurahashi, T. Ogura, S. Nakashima and H. Fujii, Journal of the American Chemical Society, 2012, 134, 20617 S. Hong, B. Wang, M. S. Seo, Y. M. Lee, M. J. Kim, H. R. Kim, T. Ogura, R. Garcia-Serres, M. Clemancey, J. M. Latour and W. Nam, Angewandte Chemie Int. Ed., 2014, 53, 6388

11 Y. Goto, S. Wada, I. Morishima and Y. Watanabe, Journal of inorganic biochemistry, 1998, 69, 241 J. Annaraj, Y. Suh, M. S. Seo, S. O. Kim and W. Nam, Chem Commun (Camb), 2005, 4529 J. Cho, S. Jeon, S. A. Wilson, L. V. Liu, E. A. Kang, J. J. Braymer, M. H. Lim, B. Hedman, K. O. Hodgson, J. S. Valentine, E. I. Solomon and W. Nam, Nature, 2011, 478, 502

14. Y. M. Kim, K. B. Cho, J. Cho, B. Wang, C. Li, S. Shaik and W. Nam, Journal of the American Chemical Society, 2013, 135, 8838

15 L. V. Liu, S. Hong, J. Cho, W. Nam and E. I. Solomon, Journal of the American Chemical Society, 2013, 135, 3286

16 C. Duboc-Toia, S. Menage, R. Y. Ho, L. Que, Jr., C. Lambeaux and M. Fontecave, Inorganic chemistry, 1999, 38, 1261

17 D. Quinonero, K. Morokuma, D. G. Musaev, R. Mas-Balleste and L. Que, Jr., Journal of the American Chemical Society, 2005, 127, 6548

18 Moenne-Loccoz, A. L. Burlingame and P. R. Ortiz de Montellano, Journal of the American Chemical Society, 2012, 134, 6673

F. E. Jenney, Jr., M. F. Verhagen, X. Cui and M. W. Adams, Science, 1999, 286, 306

M. Lombard, M. Fontecave, D. Touati and V. Niviere, The Journal of biological chemistry, 2000, 275, 115

Y. Sheng, I. A. Abreu, D. E. Cabelli, M. J. Maroney, A.-F. Miller, M. Teixeira and J. S. Valentine, Chemical Reviews, 2014, 114, 3854 Chemistry, 2007, 2007, 29

Katona, P. Carpentier, V. Niviere, P. Amara, V. Adam, J. Ohana, N. Tsanov and D. Bourgeois, Science, 2007, 316, 449 Mathe, T. A. Mattioli, O. Horner, M. Lombard, J. M. Latour, M. Fontecave and V. Niviere, Journal of the American Chemical Society, 2002, 124, 4966

C. Mathe, V. Niviere, C. Houee-Levin and T. A. Mattioli, Biophysical chemistry, 2006, 119, 38

C. Mathe, C. O. Weill, T. A. Mattioli, C. Berthomieu, C. HoueeLevin, E. Tremey and V. Niviere, The Journal of biological chemistry, 2007, 282, 22207

O. Horner, J. M. Mouesca, J. L. Oddou, C. Jeandey, V. Niviere, T. A. Mattioli, C. Mathe, M. Fontecave, P. Maldivi, P. Bonville, J. A. Halfen and J. M. Latour, Biochemistry, 2004, 43, 8815

E. Tremey, F. Bonnot, Y. Moreau, C. Berthomieu, A. Desbois, V. Favaudon, G. Blondin, C. Houee-Levin and V. Niviere, Journal of biological inorganic chemistry, 2013, 18, 815

F. Bonnot, E. Tremey, D. von Stetten, S. Rat, S. Duval, P. Carpentier, M. Clemancey, A. Desbois and V. Niviere, Angewandte Chemie Int. Ed., 2014, 53, 5926

D. Wertz and J. Valentine, in Metal-Oxo and Metal-Peroxo Species in Catalytic Oxidations, ed. B. Meunier, Springer Berlin Heidelberg, 2000, vol. 97, ch. 2, pp. 37 